\title{
ANALISIS PENGARUH PENGGUNAAN DENNIS BROWN SPLINT TERHADAP PENURUNAN DERAJAT VARUS PADA PASIEN CONGENITAL TALIPES EQUINO VARUS DI KLINIK PROMEDIK SEMARANG
}

\author{
M. Syafi'i, Siswiyanti, Reni Faridastuti Indriyani \\ Politeknik Kesehatan Surakarta Jurusan Ortotik Prostetik
}

\begin{abstract}
CTEV, Dennis Brown Splint, Ponseti Metod. Congenital varus Talipes equino is one orthopedic congenital anomalies derived from the Latin talus (ankle), pes (foot), and equinus (resemble horse) is meant heel in plantar flexion and varus position means inversion and adduction. Maintenance by way of non-operative (manipulation and immobilization) and operative therapy. Non operative using the Ponseti method in which the cast performed serial and bracing. Bracing called dennis brown splint / foot abduction brace is used to maintain the foot in abduction and dorsiflexion position. To determine the effect of the use of dennis brown splint on the degree of varus in patients CTEV. This research is a retrospective case-control approach. Sampling using consecutive sampling. The subject of research as many as 15 samples. All samples are given modality busing dennis brown splint. Test requirements obtained by normality test $p<0.05$, so the data is not normally distributed, then the statistical analysis used was Wilcoxon. Wilcoxon statistical test showed that there was no effect of a decrease in the degree of varus with pre-post test without grouping right foot $p=0.103$, and the grouping of the unilateral and bilateral leg on the right foot $p=0.317, p=0.156$ ( $p>$ $0.05)$, as well as pre -Post test without grouping on the left foot $p=0.044(p<0.05)$ means that there is an influence, the grouping of the unilateral and bilateral leg on the left leg $p=0.102$ and $p=0.151$ ( $p>0.05)$. According to the results of statistic analisis concluded there was no effect of the use of dennis brown splint to decrease the degree of varus in patients CTEV.
\end{abstract}

Keywords: CTEV, Dennis Brown Splint, Ponseti Metod

\begin{abstract}
Abstrak : CTEV, Dennis Brown Splint, Metode Ponseti. Congenital Talipes equino varus adalah salah satu anomali ortopedik kongenital yang berasal dari bahasa latin talus (ankle), pes (kaki), dan equinus (meyerupai kuda) yang dimaksud tumit dalam posisi plantar fleksi dan varus berarti inversi dan adduksi. Perawatannya dengan cara nonoperatif (manipulasi dan immobilisasi) dan terapi operatif. Non operatif menggunakan metode ponseti dimana dilakukan serial cast dan bracing. Bracing yang disebut dennis brown splint / foot abduction brace digunakan untuk mempertahankan kaki dalam posisi abduksi dan dorsofleksi. Penelitian ini bertujuan untuk mengetahui pengaruh penggunaan dennis brown splint terhadap derajat varus pada pasien CTEV. Jenis penelitian berupa case control dengan pendekatan retrospektif. Penarikan sampel menggunakan consecutive sampling. Subjek penelitian sebanyak 15 sampel. Semua sampel diberikan modalitas dengan menggunakan dennis brown splint. Uji persyaratan dengan uji normalitas didapat $\mathrm{p}<0,05$ sehingga data tidak berdistribusi normal, maka
\end{abstract}


analisis statistik yang digunakan adalah Wilcoxon. Uji statistik wilcoxon didapatkan tidak ada pengaruh penurunan derajat varus dengan pre-post test tanpa pengelompokan kaki kanan $\mathrm{p}=0,103$, dan pengelompokan kaki yang unilateral dan bilateral pada kaki kanan $\mathrm{p}=0,317, \mathrm{p}=0,156(\mathrm{p}>0,05)$, serta pre-post test tanpa pengelompokan pada kaki kiri $\mathrm{p}=0,044(\mathrm{p}<0,05)$ berarti ada pengaruh, pengelompokan kaki yang unilateral dan bilateral pada kaki kiri $\mathrm{p}=0,102$ dan $\mathrm{p}=0,151(\mathrm{p}>0,05)$. Menurut hasil analisis statistik dapat disimpulkan bahwa tidak ada pengaruh penggunaan dennis brown splint terhadap penurunan derajat varus pada pasien CTEV.

Kata Kunci : CTEV, Dennis Brown Splint, Metode Ponseti.

\section{PENDAHULUAN}

Bayi lahir dengan sehat serta memiliki anggota tubuh yang lengkap dan sempurna merupakan harapan seluruh keluarga. Namun ternyata tidak semua bayi beruntung karena ada beberapa bayi yang lahir kurang sempurna karena mengalami kelainan bentuk anggota tubuh. Salah satu kelainan bawaan yang sering dijumpai pada bayi adalah kaki bengkok Congenital Talipes Equino Varus (CTEV). CTEV adalah salah satu anomali ortopedik kongenital yang sudah lama dideskripsikan oleh Hippocrates pada tahun 400 SM (Miedzybrodzka, 2002).

Congenital talipes equino varus (CTEV) atau club foot adalah istilah medis yang diterapkan pada deformitas kaki pengkor yang didapat saat lahir, dimana kaki belakang equinus (mengarah ke bawah), varus (mengarah ke dalam/ medial), dan metatarsus adduktus (mendekati tubuh). Tulang calcaneus, navikulare, dan cuboid terotasi ke arah medial terhadap talus, dan tertahan dalam posisi adduksi serta inversi oleh ligamen dan tendon. Sebagai tambahan, tulang metatarsal pertama lebih fleksi terhadap daerah plantar. (Rao, 2012)

Kondisi ini bervariasi dari yang ringan dimana dapat dikoreksi, sampai yang parah dengan deformitas yang kaku.
Hal ini akan membedakan dalam penerapann penanganannya. (Rao, 2012)

Congenital talipes equino varus terdiri dari kombinasi beberapa deformitas, yaitu (1) adduksi pada forefoot (2) supinasi pada midfoot (3) varus pada sendi subtalar, (4) equinus pada sendi ankle, dan (5) rotasi internal tibial. (Reddy, 2009)

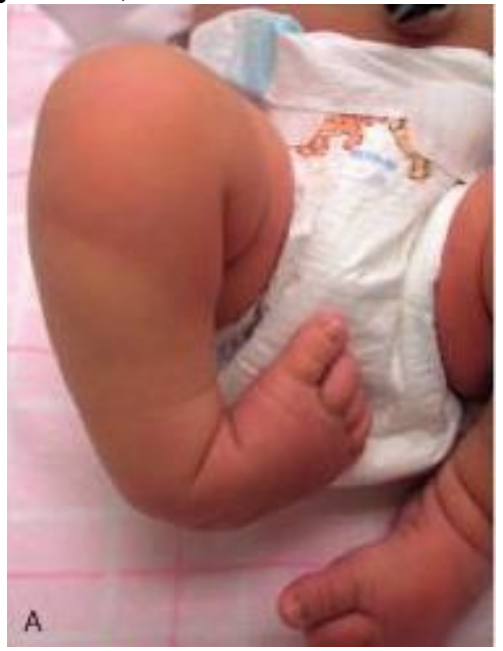

Gambar 1. Congenital talipes equino varus (Herring, 2013)

Kelainan congenital talipes equino varus, yaitu sebuah deformitas yang mudah untuk didiagnosis, namun sulit untuk mengoreksi dengan hasil yang sempurna, meskipun di tangan seorang ahli bedah orthopedi yang berpengalaman. Talipes equino varus berasal dari bahasa latin talus (ankle), pes (kaki), dan equinus (meyerupai kuda) yang dimaksud tumit 
dalam posisi plantar fleksi dan varus berarti inversi dan adduksi. (Ariffudin, 2010)

Congenital talipes equino varus ditemukan pada hieroglif Mesir dan perawatannya dijelaskan oleh Hipokrates pada 400 SM dengan cara memanipulasi kaki dengan lembut untuk kemudian dipasangi perban. Sampai saat ini, perawatan modern juga masih mengandalkan manipulasi dan immobilisasi. Manipulasi dan immobilisasi serial yang dilakukan secara hati-hati diikuti pemasangan gips adalah metode perawatan modern non-operatif. Cara imobilisasi yang saat ini mungkin paling efektif adalah metode Ponseti. Metode ini dapat mengurangi perlunya operasi. Walaupun demikian, masih banyak kasus yang membutuhkan terapi operatif. (Cahyono, 2012)

Insidens CTEV bervariasi, bergantung dari ras dan jenis kelamin. Insidens CTEV dilaporkan sekitar 1 sampai 2 per 1000 kelahiran, dengan kejadian bilateral $50 \%$ kasus, dengan insiden yang beragam pada beberapa negara, seperti di Amerika Serikat insiden clubfoot 2,29 per 1000 kelahiran hidup, di Caucasia 1,6 per 1000, di Cina dan Jepang 0,5 per 1000, di Maori dan kepulauan pasifik lain 6-7 per 1000, di Polynesia 6,81 per 1000 , di UK prevalensi sesuai survei nasional 0,89 per 1000 kelahiran hidup meskipun 1,242 atau lebih besar telah dilaporkan.

Menurut Kurniawan (2013), insiden clubfoot adalah 1 dalam 1000 kelahiran hidup, dengan angka kelahiran hidup di Indonesia sekitar 4 juta setahun maka didapatkan 4000 bayi dengan clubfoot setiap tahunnya.

Frekuensi clubfoot dari populasi umum adalah 1:700 sampai 1:1000 kelahiran hidup dimana anak laki-laki dua kali lebih sering daripada perempuan. Insidensi pada laki-laki $65 \%$ kasus, sedangkan pada perempuan $30-40 \%$ kasus. (Subagyo, 2013)

Penyebab utama CTEV tidak diketahui (idiopatik). Tetapi diduga ada hubungannya dengan: persistence of fetal positioning, genetic, cairan amnion dalam ketuban yang terlalu sedikit pada waktu hamil (oligohidramnion), neuromuscular disorder (kadang kala ditemukan bersamaan dengan kelainan lain seperti spina bifida atau displasia dari rongga panggul). (Reddy, 2009)

Ada beberapa teori yang kemungkinan berhubungan dengan CTEV: (a) Teori kromosomal, antara lain defek dari sel germinativum yang tidak dibuahi dan muncul sebelum fertilisasi, (b) Teori embrionik, antara lain defek primer yang terjadi pada sel germinativum yang dibuahi (dikutip dari Irani dan Sherman) yang mengimplikasikan defek terjadi antara masa konsepsi dan minggu ke-12 kehamilan, (c) Teori otogenik, yaitu teori perkembangan yang terhambat, antara lain hambatan temporer dari perkembangan yang terjadi pada atau sekitar minggu ke-7 sampai ke-8 gestasi. Pada masa ini terjadi suatu deformitas clubfoot yang jelas, namun bila hambatan ini terjadi setelah minggu ke-9, terjadilah deformitas clubfoot yang ringan hingga sedang. Teori hambatan perkembangan ini dihubungkan dengan perubahan pada faktor genetic yang dikenal sebagai "Cronon". "Cronon" ini memandu waktu yang tepat dari modifikasi progresif setiap struktur tubuh semasa perkembangannya. Karenanya, clubfoot terjadi karena elemen disruptif (lokal maupun umum) yang menyebabkan perubahan faktor genetic (cronon), (d) Teori fetus, yakni blok 
mekanik pada perkembangan akibat intrauterine crowding, (e) Teori neurogenik, yakni defek primer pada jaringan neurogenik, (f) Teori amiogenik, bahwa defek primer terjadi di otot, (g) Sindrom Edward, yang merupakan kelainan genetic pada kromosom nomer 18, (h) Pengaruh luar seperti penekanan pada saat bayi masih didalam kandungan dikarenakan sedikitnya cairan ketuban (oligohidramnion), (i) Dapat dijumpai bersamaan dengan kelainan bawaan yang lain seperti spina bifida.

Menurut Scher (2006) sekitar 9095\% kasus CTEV dapat ditangani dengan cara konservatif yaitu dengan metode ponseti. Seperti dilaporkan WHO, metode Ponseti adalah sebuah prosedur yang simpel, minimal invasif dancost efective untuk penatalaksaanan clubfoot dengan tingkat keberhasilan 98 persen di tangan dokter yang sudah terdidik dengan baik dan usia anak saat pertama kali metoda Ponseti dimulai. (Kurniawan, 2013)

Metode koreksi Ponseti dicapai dengan membalikkan arah rotasi ini. Koreksi dicapai secara bertahap dengan gips serial. Tehnik Ponseti memperbaiki deformitas dengan cara merotasikan kaki disekitar caput talus secara bertahap selama beberapa minggu pengegipan tersebut. Protokol Ponseti selanjutnya adalah memakai brace (bracing) untuk mempertahankan kaki dalam posisi abduksi dan dorsofleksi. (Staheli, 2009)

Dalam penanganan ponseti ini, ortotis prostetis adalah salah satu yang sangat berperan dalam pemberian pelayanan kesehatan pada CTEV dengan membuatkan ortosis berupa bracing yang disebut dennis brown splint / foot abduction brace. Dennis brown splint ini adalah alat bantu yang diposisikan overcorection pada kaki yang terkena CTEV setelah perlakuan serial cast selesai.

Berdasarkan yang telah disampaikan diatas, peneliti tertarik untuk mengamati dan mengetahui "Pengaruh penggunaan dennis brown splint terhadap penurunan derajat varus pada pasien CTEV"

Tujuan penelitian ini adalah untuk mengetahui pengaruh penggunaan dennis brown splint terhadap penurunan derajat varus pada pasien CTEV

Dengan penelitian ini maka diharapkan akan mendapatkan berbagai macam manfaat yang dapat diambil anttara lain: (1) Bagi peneliti, penelitian ini diharapkan akan menambah ilmu pengetahuan dan memberikan solusi pemecahan masalah bagi peneliti tentang pengaruh penggunaan dennis brown splint terhadap penurunan derajat varus pada pasien CTEV, (2) Bagi Ortotis Prostetis, penelitian ini diharapkan akan menambah keilmuan dan wawasan dalam bidang ortotik prostetik dan dapat menjadi bahan pertimbangan dalam merencanakan, dan melaksanakan Pelayanan Ortotik Prostetik, (3) Bagi institusi, menambah pengetahuan bagi pendidik dan mahasiswa tentang pengaruh penggunaan dennis brown splint terhadap penurunan derajat varus pada pasien CTEV.

\section{METODE PENELITIAN}

Jenis penelitian yang digunakan adalah rancangan penelitian berupa case control dengan pendekatan retrospektif. Penelitian case control atau kasus kontrol merupakan suatu penelitian (survei) analitik yang menyangkut bagaimana faktor risiko dipelajari dengan menggunakan pendekatan retrospektif. Pada studi kasus-kontrol, observasi atau 
pengukuran terhadap variabel bebas dan tergantung tidak dilakukan dalam satu waktu, melainkan variabel tergantug (efek) dilakukan pengukuran terlebih dahulu, baru meruntut kebelakang untuk mengukur variabel bebas (faktor risiko). Studi kasus-kontrol sering disebut studi retrospektif karena faktor risiko diukur dengan melihat kejadian masa lampau untuk mengetahui ada tidaknya faktor risiko yang dialami. (Setiawan, 2010)

Subyek dalam penelitian adalah semua pasien CTEV yang mendapatkan penanganan ortotis prostetis dengan diberikan Dennis brown splint. Populasi dari penelitian ini adalah semua pasien CTEV yang membuat alat dennis brown splint di Klinik Promedik dari bulan Januari - April 2015 sebanyak 29 sampel. Besar sampel yang dibutuhkan dalam penelitian ini adalah 15 sampel data di Klinik Promedik Semarang.

Penarikan sampel menggunakan consecutive sampling yaitu setiap sampel yang memenuhi kriteria penelitian dimasukkan dalam penelitian kurun waktu tertentu, sehingga jumlah pasien yang diperlukan terpenuhi. (Sastroasmoro, 2008)

Pasien CTEV dengan metode konservatif di Klinik Promedik periode Januari 2014 sampai April 2015 yang memenuhi krieria inklusi sebanyak 15 sampel. Kriteria inklusi pada penelitian ini adalah : (1) pasien CTEV yang telah menggunakan denis brown splint, (2) pasien yang berusia $1-12$ bulan, (3) penanganan CTEV dengan konservatif, sedangkan kriteria eksklusi sampel pada penelitian ini adalah : (1) pasien CTEV dengan komplikasi dan gangguan yang dapat mempengaruhi peningkatan derajat keparahan CTEV menggunakan ortosis, (2) pasien CTEV post operasi. Parameter yang digunakan untuk mengukur derajat varus adalah goniometer dengan alat tulis untuk mencatat data pada rekam medis.

Pada tahap persiapan meliputi : (1) meminta izin melakukan penelitian kepada pihak di Klinik Promedik, (2) melakukan konsultasi ke kepala klinik selaku ortotis prostetis. Subyek penelitian adalah semua pasien dengan diagnosis CTEV pasca penanganan serial gip yang datang ke Klinik Promedik Januari 2014 sampai April 2015 yang memenuhi kriteria inklusi. Pengumpulan data menngunakan data sekunder dimana data sekunder penelitian diperoleh dari data di Klinik Promedik dan data rekam medis pada dokter sp.OT yang bekerjasama dengan Klinik Promedik. Langkah pertama, pendekatan kepada tenaga lapangan (semua tenaga medis di klinik Promedik dan yang bekerjasama dengan klinik tersebut) yang bertugas memberikan penanganan pada pasien selama penelitian. Langkah kedua, pengumpulan data responden dari data rekam medis untuk mengetahui derajat varus sebelum digunakan dennis brown splint dan derajat varus setelah pemberian modalitas yang memenuhi kriteria inklusi.

Data yang sudah direkapitulasi untuk hasil pengukuran derajat varus pada CTEV baik sebelum dan sesudah dilakukannya perlakuan, kemudian dilakukan analisis data secara statistik sebagai berikut :

Uji normalitas data digunakan untuk mengetahui apakah data berdistribusi normal atau tidak. Uji normalitas menggunakan Shapiro-Wilk test jika subjek $\leq 50$. Jika subjek $>50$, maka uji normalitas menggunakan Kolmogorov- Smirnov . Data dikatakan berdistribusi normal jika nilai $p>0,05$. Apabila data berdistribusi normal, maka 
menggunakan analisis parametrik. Jika data tidak berdistribuasi normal, maka menggunakan analisis non parametrik.

Uji Beda pre dan post test digunakan untuk mengetahui hasil perbedaan derajat varus pada saat sebelum dan sesudah mendapatkan perlakuan. Kelompok sebelum dan sesudah perlakuan merupakan kelompok data berpasangan dan 2 kelompok. jika data berdistribusi normal, maka analisis statistik yang digunakan adalah dependent $t$ test. Tetapi Jika data tidak berdistribusi normal, maka analisis statistik yang digunakan adalah Wilcoxon. Jika $\mathrm{P} \leq 0,05$ maka data terpenuhi dan jika $\mathrm{P}>0,05$ maka tidak terpenuhi.

\section{HASIL PENELITIAN}

Tabel 1

Karakteristik Subyek Penelitian Berdasarkan Umur

\begin{tabular}{ccc}
\hline \multirow{2}{*}{ Karakteristik } & \multicolumn{2}{c}{ Subyek Penelitiaan } \\
\cline { 2 - 3 } & Jumlah & Persen \\
\hline 3 & 1 & $6,7 \%$ \\
4 & 4 & $26,7 \%$ \\
5 & 2 & $13,3 \%$ \\
6 & 3 & $20 \%$ \\
7 & 1 & $6,7 \%$ \\
8 & 1 & $6,7 \%$ \\
11 & 1 & $6,7 \%$ \\
12 & 2 & $13,3 \%$ \\
\hline Jumlah Subyek & 15 & $100 \%$ \\
\hline
\end{tabular}

Karakteristik penelitiaan

berdasarkan umur dengan subyek penelitian 15 orang didapat hasil umur minimal 3 bulan, umur maksimal 12 bulan. Jumlah sample yang berumur 3 bulan sebanyak 1 sample dengan persentasenya $6,7 \%$, untuk umur 4 bulan sebanyak 4 sample $(26,7 \%)$, sedang yang berumur 5 bulan sebanyak 2 sample $(13,3$ $\%)$, untuk umur 6 bulan sebanyak 3 sample (20\%), pada umur 7, 8, 11 bulan dimana masing-masing jumlahnya sample dengan persentase $6,7 \%$. Sisanya untuk umur 12 bulan sebanyak 2 sample $(13,3 \%)$.

Tabel 2

\begin{tabular}{|ccc|}
\multicolumn{3}{c}{$\begin{array}{c}\text { Karakteristik Subyek Penelitian } \\
\text { Berdasarkan Jenis Kelamin }\end{array}$} \\
\hline \multirow{2}{*}{ Karakteristik } & \multicolumn{2}{c}{ Subyek Penelitiaan } \\
\cline { 2 - 3 } & Jumlah & Persen \\
\hline aki-laki & 10 & $66,7 \%$ \\
Perempuan & 5 & $33,3 \%$
\end{tabular}

\begin{tabular}{ccc}
\hline Jumlah Subyek & 15 & $100 \%$ \\
\hline Dapat dilihat bahwa jumlah laki-
\end{tabular} laki sebanyak 10 sample dengan persentase $66,7 \%$, sedang perempuan sebanyak 5 sample dengan persentase $33,3 \%$. Ini sejalan dengan teori dimana angka kejadian pada anak laki-laki dua kali lebih sering daripada perempuan.

Tabel 3

Keadaan Subyek Penelitian

Berdasarkan Kelompok Kaki Yang Terkena

\begin{tabular}{lcc}
\hline \multirow{2}{*}{ Karakteristik } & \multicolumn{2}{c}{ Subyek Penelitiaan } \\
\cline { 2 - 3 } & Jumlah & Persen \\
\hline Unilateral & 5 & $33,3 \%$ \\
Bilateral & 10 & $66,7 \%$ \\
\hline Jumlah Subyek & 15 & $100 \%$ \\
\hline \multicolumn{2}{c}{ Pada penelitiaan ini, paling banyak }
\end{tabular}
adalah subyek yang terkena pada kedua sisi kaki (bilateral), dimana bilateral sebanyak 10 anak dengan persentase $66,7 \%$ dan untuk yang salah satu kelompok kaki yang terkena (unilateral) sebanyak 5 anak dengan persentase $33,3 \%$.

Tabel 4

Keadaan Berdasarkan Pengukuran Derajat Varus Sebelum Perlakuan

\begin{tabular}{lccccc}
\hline & N & Min & Maks & Rerata & $\begin{array}{l}\text { Standar } \\
\text { deviasi }\end{array}$ \\
\hline $\begin{array}{l}\text { Pre test } \\
\text { kanan }\end{array}$ & 12 & -70 & 20 & $-6,67$ & 22,191 \\
\hline $\begin{array}{l}\text { Pre test } \\
\text { kiri }\end{array}$ & 13 & -70 & 20 & $-7,69$ & 20,577 \\
\hline
\end{tabular}


Pada tabel 4 menjelaskan bahwa subyek dengan sisi kaki kanan yang terkena sebanyak 12 anak dan untuk sisi kaki kiri 13 anak (1) keadaan sebelum perlakuan pada kaki kanan dengan nilai derajat minimumnya -70 , maksimum derajat varus 20, rerata derajat varus $-6,67$ dan standar deviasi 22,191.

karakteristik sebelum perlakuan pada kaki kiri dengan nilai derajat minimumnya -70 , maksimum derajat varus 20 , rerata derajat varus $-7,69$ dan standar deviasi 20,577.

Tabel 5

Keadaan Berdasarkan Pengukuran Derajat Varus Sesudah Perlakuan

\begin{tabular}{lccccc}
\hline & N & Min & Maks & Rerata & $\begin{array}{l}\text { Standar } \\
\text { deviasi }\end{array}$ \\
\hline $\begin{array}{l}\text { Post } \\
\text { test } \\
\text { kanan }\end{array}$ & 12 & -20 & 0 & $-9,58$ & 4,981 \\
\hline $\begin{array}{l}\text { Post } \\
\text { test } \\
\text { kiri }\end{array}$ & 13 & -20 & -5 & $-11,15$ & 4,634 \\
\hline & Pada & tabel & diatas, & menjelaskan
\end{tabular}

bahwa subyek dengan sisi kaki kanan yang terkena sebanyak 12 anak dan untuk sisi kaki kiri 13 anak (1) keadaan sebelum perlakuan pada kaki kanan dengan nilai derajat minimumnya -20 , maksimum derajat varus 0 , rerata derajat varus 9,58dan standar deviasi 4,981. karakteristik sebelum perlakuan pada kaki kiri dengan nilai derajat minimumnya -20 , maksimum derajat varus -5 , rerata derajat varus -11,15dan standar deviasi 4,634.

\section{Tabel 6}

Hasil Uji Statistik Penurunan Derajat Varus Sebelum Dan Sesudah Perlakuan

\begin{tabular}{lcccc}
\hline $\begin{array}{c}\text { Pre Test }- \\
\text { Post test }\end{array}$ & $\begin{array}{c}\text { Nilai } \\
\text { naik }\end{array}$ & $\begin{array}{c}\text { Nilai } \\
\text { turun }\end{array}$ & $\begin{array}{c}\text { Nilai } \\
\text { tetap }\end{array}$ & $\begin{array}{c}\text { Signifikansi } \\
(\boldsymbol{p})\end{array}$ \\
\hline Kaki kanan & 8 & 1 & 3 & 0,103 \\
Kaki kiri & 10 & 1 & 2 & 0.044 \\
\hline
\end{tabular}

Dari tabel diatas dapat diketahui bahwa nilai naik derajat varus untuk kaki kanan 8 dan kaki kiri 10, untuk nilai yang menurun atau derajat varusnya bertambah sebanyak 1 untuk masing-masing kaki. Derajat varus yag tetap sebelum dan setelah perlakuan untuk kaki kanan sebanyak 3 dan kiri 2. Nilai $p$ untuk pre post derajat varus pada kaki kanan adalah $p=0,103$ dimana $p>0.05$. Ini menunjukkan bahwa tidak terdapat penurunan derajat varus antara sebelum perlakuan dan sesudah diberikan perlakuan. Untuk uji Wilcoxon pada kaki kiri didapatkan nilai $p=0,044$ dimana $p<$ 0.05. Ini menunjukkan bahwa terdapat penurunan derajat varus antara sebelum perlakuan dan sesudah diberikan perlakuan.

Untuk uji Wilxoson pada kelompok unilateral dan bilateral menggunakan select cases untuk pengelompokan data yang akan diuji.

\section{Tabel 7}

\section{Hasil Uji Statistik Penurunan Derajat} Varus Sebelum Dan Sesudah Perlakuan Kelompok Unilateral

\begin{tabular}{lllll}
\multicolumn{5}{c}{ Kelompok Unilateral } \\
\hline $\begin{array}{l}\text { Pre Test }- \\
\text { Post test }\end{array}$ & $\begin{array}{c}\text { Nilai } \\
\text { naik }\end{array}$ & $\begin{array}{c}\text { Nilai } \\
\text { turun }\end{array}$ & $\begin{array}{c}\text { Nilai } \\
\text { tetap }\end{array}$ & $\begin{array}{c}\text { Signifikansi } \\
(\boldsymbol{p})\end{array}$ \\
\hline $\begin{array}{l}\text { Kaki } \\
\text { kanan }\end{array}$ & 1 & 0 & 1 & 0,317 \\
$\begin{array}{l}\text { Kaki } \\
\text { kiri }\end{array}$ & 3 & 0 & 0 & 0.102 \\
\hline
\end{tabular}

Dari tabel diatas dapat diketahui bahwa nilai naik derajat varus untuk kaki kanan sebanyak 1 sampel dan kaki kiri 3 sampel, dan tidak ada nilai yang menurun untuk masing-masing kaki. Nilai tetap untuk kaki kanan sebanyak 1 sampel. Nilai $p$ untuk pre post derajat varus pada kaki kanan adalah $p=0,317$ dimana $p>$ 0.05. Ini menunjukkan bahwa tidak terdapat penurunan derajat varus antara 
sebelum perlakuan dan sesudah diberikan perlakuan. Untuk uji Wilcoxon pada kaki kiri didapatkan nilai $p=0,102$ dimana $p>$ 0.05. Ini menunjukkan bahwa tidak ada pengaruh sebelum dan sesudah dilakukan perlakuan.

Untuk uji Wilxoson pada kelompok unilateral dan bilateral menggunakan select cases untuk pengelompokan data yang akan diuji.

\section{Tabel 8.}

\begin{tabular}{|c|c|c|c|c|}
\hline $\begin{array}{l}\text { Hasil L } \\
\text { Varus S }\end{array}$ & $\begin{array}{l}\text { Stati } \\
\text { Sum } \\
\text { Kelo }\end{array}$ & $\begin{array}{l}\mathbf{P e} \\
\mathrm{nS}\end{array}$ & ? & $\begin{array}{l}\text { Perajat } \\
\text { rlakuan }\end{array}$ \\
\hline $\begin{array}{l}\text { Pre Test - } \\
\text { Post test } \\
\end{array}$ & $\begin{array}{l}\text { Nilai } \\
\text { naik }\end{array}$ & $\begin{array}{l}\text { Nilai } \\
\text { turun }\end{array}$ & $\begin{array}{l}\text { Nilai } \\
\text { tetap }\end{array}$ & $\begin{array}{c}\text { Signifikansi } \\
(p)\end{array}$ \\
\hline $\mathrm{i} \mathrm{kal}$ & 7 & 1 & 2 & 0,156 \\
\hline i kiri & 7 & 1 & 2 & 0.151 \\
\hline
\end{tabular}

Dari tabel diatas dapat diketahui

bahwa nilai naik derajat varus untuk kaki kanan dan kaki kiri sebanyak 7 sampel, dan nilai yang menurun untuk masingmasing kaki 1 sampel, sedangkan nilai tetap untuk kaki kanan dan kiri sebanyak 2 sampel. Nilai $p$ untuk pre post derajat varus pada kaki kanan adalah $p=0,156$ dimana $p>0.05$. Ini menunjukkan bahwa tidak terdapat penurunan deraja varus antara sebelum perlakuan dan sesudah diberikan perlakuan. Untuk uji Wilcoxon pada kaki kiri didapatkan nilai $p=0,151$ dimana $p>0.05$. Ini menunjukkan bahwa tidak ada pengaruh sebelum dan sesudah dilakukan perlakuan.

\section{PEMBAHASAN}

Pada penelitian ini subjek sebanyak 15 subyek, masing-masing subjek menggunakan dennis brown splint. Pengukuran derajat varus didapat dari data rekam medis yang dalam pengukurannya menggunakan rontgen maupun goniometer. Intervensi yang diberikan adalah dengan pemasangan dennis brown splint selama 3 bulan, dan harus dipakai sepanjang hari.

Hasil uji hipotesis yang telah dilakukan bahwa tidak ada pengaruh penggunaan dennis brown splint terhadap penurunan derjat varus pada pasien CTEV untuk kaki kanan dengan $p=0,103$, namun untuk kaki kiri ada pengaruh penggunaan dennis brown splint terhadap penurunan derajat varus pada pasien CTEV dengan $p=0,044$ dimana $p<0,05$.

Selain dari uji hipotesis diatas, uji dengan pengelompokan unilateral dan bilateral menyatakan bahwa hipotesis pada kaki kanan adalah hipotesis ditolak atau tidak ada pengaruh penggunaan dennis brown splint terhadap penurunan derajat varus pada pasien CTEV $p=$ $0,317, p=0,156(p>0,05)$. Untuk kaki kiri hipotesis menurut pengelompokan juga hipotesis ditolak dengan nilai $p=0,102$ untuk yang unilateral, yang bilateral $p=$ 0,151 . Ini menunjukan tidak ada pengaruh penggunaan dennis brown splint terhadap penurunan derajat varus.

Penolakan hipotesis ini dikarenakan data pre dan post test ada yang menurunnya derajat varus ke sudut valgus yang sangat ekstrim setelah dilakukan serial cast dengan hasil range sebaran data minimum dan maksimum sebelum perlakuan kaki kanan dan kiri selisihnya 90 dan derajat varus setelah dilakukannya serial cast sudah dalam penurunan derajat varus sehingga dennis brown splint dapat disimpulkan bahwa tidak mengoreksi namun mempertahankan hasil serial cast yang telah dilakukan. Ini sama dengan teori ponseti bahwa penggunaan brace setelah kaki diperbaiki sepenuhnya pada serial cast sehingga fungsi brace hanya untuk 
mempertahankan hasil koreksi dan mencegah kekambuhan.

Ini tidak sejalan dengan penelitian yang dilakukan oleh Bouchoucha, S. et al dengan judul Early results of the Ponseti method using the Steenbek foot abduction brace: a prospective study of 95 feet dan penelitian Yamamoto et al (1990) "Treatment Of Congenital Club Foot With A Modified Denis Browne Splint.". Dengan hasilnya semua kaki yang dipakaikan brace selama periode tertentu menunjukan koreksi yang bagus, dengan menggunakan brace tersebut.

Penelitian ini juga dapat dikelompokan berdasarkan hasilnya yaitu (1) dennis brown brace dapat mengoreksi derajat varus pada CTEV dimana derajat varus dari $0^{\circ}-20^{\circ}$, (2) dennis brown splint hanya untuk mempertahankan hasil serial cast bilamana derajat varus setelah serial cast sudah $-10^{\circ}$ sampai dengan $20^{\circ}$ ini menunjukan derajat varusnya dalam posisi valgus dan (3) dennis brown splint tidak berpengaruh pada subjek CTEV yang sudut varusnya telah terkoreksi dalam posisi valgus lebih dari $15^{\circ}-20^{\circ}$.

\section{KESIMPULAN DAN SARAN}

Penelitian tentang pengaruh penggunaan dennis brown splint terhadap derajat varus pada pasien CTEV yang dilakukan di Klinik Promedik Semarang dengan jumlah subyek 15 anak dengan unilateral sebanyak 5 anak dan sisanya bilateral dengan jumlah kaki semuanya yang tekena 25 kaki. Pada uji wilxocon dengan pre-post test tanpa pengelompokan kaki kanan $p=0,103$, dan pengelompokan kaki yang unilateral dan bilateral pada kaki kanan $p=0,317, p=$ 0,156 , serta pre-post test tanpa pengelompokan pada kaki kiri $p=0,044$, pengelompokan kaki yang unilateral dan bilateral pada kaki kiri $p=0,102$ dan $p=$ 0,151. Disimpulkan dari data SPSS ini, diperoleh bahwa tidak ada pengaruh penurunan derajat varus dengan pemakaian dennis brown splint.

Pada serial cast varus telah terkoreksi, sudah dalam penurunan derajat varus sehingga dari data tabulasi ditarik kemukakan bahwa hasil penelitian ini mempunyai 3 kesimpulan mengoreksi, mempertahankan dan tidak mengoreksi. (1) dennis brown brace dapat mengoreksi derajat varus pada CTEV dimana derajat varus dari $0^{\circ}-20^{\circ}$ varus sebanyak 8 anak. (2) dennis brown splint hanya untuk mempertahankan hasil serial cast bilamana derajat varus setelah serial cast sudah $-5^{\circ}$ sampai dengan $-20^{\circ}$ ini menunjukan derajat varusnya dalam posisi valgus sebanyak 6 anak. Ini sama dengan teori ponseti dalam buku Clubfoot: Ponseti Management karya Staheli (2009) bahwa penggunaan brace setelah kaki diperbaiki sepenuhnya pada serial cast sehingga fungsi brace hanya untuk mempertahankan hasil koreksi dan mencegah kekambuhan. (3) dennis brown splint tidak berpengaruh pada subjek CTEV yang sudut varusnya telah terkoreksi dalam posisi valgus lebih dari $15^{\circ}-20^{\circ}$.

Pada penelitian ini masih terdapat beberapa kelemahan yang perlu diperbaiki pada penelitian-penelitian sejenis selanjutnya. Penelitian sejenis diharapkan dapat dilakukan dengan lebih teliti, terutama untuk mengontrol variablevariabel lain yang dapat membiaskan hasil penelitian. Pada penelitian selanjutnya disarankan untuk: (1) mencari subyek penelitian yang lebih banyak dengan mempertimbangkan derajat varus setelah serial cast yang dilakukan (2) 
penggunaan jenis alat ukur yang lebih banyak (3) perlakuan harus dikontrol dalam rentang waktu yang diteliti tersebut.

\section{DAFTAR RUJUKAN}

Ariffudin, M., 2010; Evaluasi Radiologis pada Pasien Idiopathic Clubfoot yang Diterapi dengan Metode Ponseti, UNS, Surakarta

Cahyono, B.C., 2012; Congenital Talipes Equinovarus (CTEV), FK UNEJ, Jember. vol. 39. Hal 178-183

Herring, J.A., 2013; Tachdjian's Pediatric Orthopaedics: From the Texas Scottish Rite Hospital; edisi V, Saunders elsivier, Canada

Kurniawan, A., 2012; Ponseti Atasi Clubfoot sampai 98Persen; Diakses 22/08/14

Miedzybrodzka, Z., 2002; Congenital talipes Equino-Varus (Clubfoot): a disorder of the foot but not the hand; Journal Anatomy 202:37-2

Rao, Bhasakr, 2012; Comparative Study of Management of CTEV by Turco's Procedure and Ponsetti's Technique; Bethestha Orthopedic and Joint Replacement Centre, Hubli

Reddy, K. K., 2009; Correction of Clubfoot by Ponseti Method - Our Experience; M S Ramaiah Medical College, Bangalore.

Setiawan, A. dan Saryono, 2010; Metodologi Penelitian Kebidanan; Medika, Jakarta

Sastroasmoro, S. \& Ismael, S., 2008; Dasar - Dasar Metodologi Penelitian Klinis; Binarupa Aksara, Jakarta, hal 49

Staheli, Lynn., 2009; Clubfoot: Ponseti Management; Third Edition, Global HELP, USA

\author{
Subagyo, 2013; Congenital talipes \\ Equinovarus (CTEV); diakses \\ 03/12/2014 \\ Yamamoto, H., \& Furuya, K., 1990; \\ Treatment Of Congenital Club \\ Foot With A Modified Denis \\ Browne Splint; The Journal of \\ Bone and Surgery, vol 72-B hal. \\ 460-463
}

